\title{
圈Sociología
}

Cortez López, M. A. (2019). Resultados políticos de los conflictos socio ambientales eléctricos en Chile. Revista de Sociologia, 34(1), 102-121. doi:

\section{Resultados políticos de los conflictos socio-ambientales eléctricos en Chile}

\section{[Political outcomes of the socio-environmental conflicts in Chile]}

\author{
Mauricio Andrés Cortez López \\ Universidad Tecnológica de Chile INACAP
}

\begin{abstract}
Resumen
El presente estudio analiza dos casos de conflictividad socio-ambiental eléctrica en Chile, los cuales modificaron sustancialmente las dinámicas políticas y el diseño territorial de las localidades en donde se insertaron. Para comprender estos casos, se rastrean los principales hitos políticos de los conflictos, a partir de una aproximación metodológica que consideró la etnografía y el rastreo de procesos. Mediante esta aproximación, se identifica que el conflicto desborda la dimensión socio-ambiental para situarse en una socio-territorial, transformando los mecanismos del poder fundamentalmente en tres aspectos: agenda política, estructura institucional y liderazgos.
\end{abstract}

Palabras clave: conflicto socio-ambiental, conflicto socio-territorial, resultados políticos, movimientos sociales, agenda política.

\begin{abstract}
This paper analizes two cases of electrical socioenvironmental conflict in Chile. They modified substantially the political dynamics and territorial design of the locations where they took place in Chile. To understand these cases, the main political milestones of the conflicts are traced, using a methodological approximation that considered ethnography and process tracing. Through this approach, it can identified that the conflict goes beyond the socio-environmental dimension addressing a socio-territorial dimension too. Thus, the mechanism of power turn into three main aspects: political agenda, institutional structure and leadership.
\end{abstract}

Keywords: socio-environmental conflict, socioterritorial conflict, political outcomes, social movements, political agenda.

Contacto: La comunicación sobre este artículo debe ser enviada a Mauricio Andrés Cortez López, email: mcl.mauricio@gmail.com

Financiamiento: Fondo Nacional de Desarrollo Científico y Tecnológico FONDECYT N 1151215.

Agradecimientos: El autor agradece la colaboración Antoine Maillet y Kapris Tabilos, quienes contribuyeron a que el manuscrito lograra una mejor calidad y articulación interdisciplinaria. 


\section{INTRODUCCIÓN}

En la última década se han multiplicado los conflictos socio-ambientales en el continente, lo cual tiene como correlato el aumento de las aproximaciones teóricas y metodológicas con respecto a su estudio, fundamentalmente asociado a la productividad o resultados de dichos conflictos (Amenta, Care, Chiarello \& Sum, 2010; Correa \& Rodríguez, 2005, Delamaza, Maillet \& Martínez, 2017). A pesar del aumento de estos estudios y de la variedad de las aproximaciones, existe un vacío, tanto teórico como empírico, en cuanto a los resultados políticos que estos conflictos generan en la escala territorial local. Estos resultados se expresan como un proceso multidimensional que involucra profundamente a los mecanismos y dinámicas políticas sobre la toma de decisiones y la dirección que tendrá el territorio en relación a su diseño y planificación.

Según señala el Instituto Nacional de Derechos Humanos, en el año 2018 en Chile existían 116 conflictos, de los cuales el 38\% (la mayoría) corresponde al sector energía. A éste lo sigue el sector minero, con un 28\%. Las regiones con mayor cantidad de conflictos socio-ambientales son la Metropolitana, Los Lagos y Atacama (Instituto Nacional de Derechos Humanos (INDH), 2018).

Para dar cuenta los resultados políticos a nivel territorial, se ha optado por un estudio cualitativo de carácter descriptivo de dos casos de conflictividad socio-ambiental en Chile, que tuvieron incidencia política a nivel local. Estos casos comprenden el área de generación eléctrica en el centro y el norte de Chile. Se investigaron los conflictos socio-ambientales asociados a los proyectos Hidroeléctrico Alto Maipo, de la compañía AES Gener, en la comuna de San José de Maipo, y el proyecto Termoeléctrico Punta Alcalde, de la compañía Enel, ubicado en la comuna de Huasco.

La literatura sobre conflictos socio-ambientales señala una serie de ámbitos de incidencia política, fundamentalmente en relación a: i) movimientos sociales, coalición de actores, construcción de agendas políticas e institucionalidad (Bosi \& Uba, 2009; Correa \& Rodríguez, 2005); ii) liderazgos, repertorios de movilización (Medel \& Somma, 2016); y iii) nuevas formas de territorialidad (Aliste \& Stamm, 2014; Altschuler, 2013; entre otros).

Movimientos; liderazgos sociales y políticos; cambios en la agenda política local; nuevas institucionalidades locales ligadas a acciones desde las políticas públicas nacionales; todo ello permite sostener que los conflictos no son sólo un conjunto de acciones específicas en contra de los proyectos eléctricos, delimitados en el tiempo y en el espacio, sino que además tienen la capacidad de transformar políticamente, con mayor o menor grado, el desarrollo de los territorios en los que se despliegan este tipo de conflictos. 

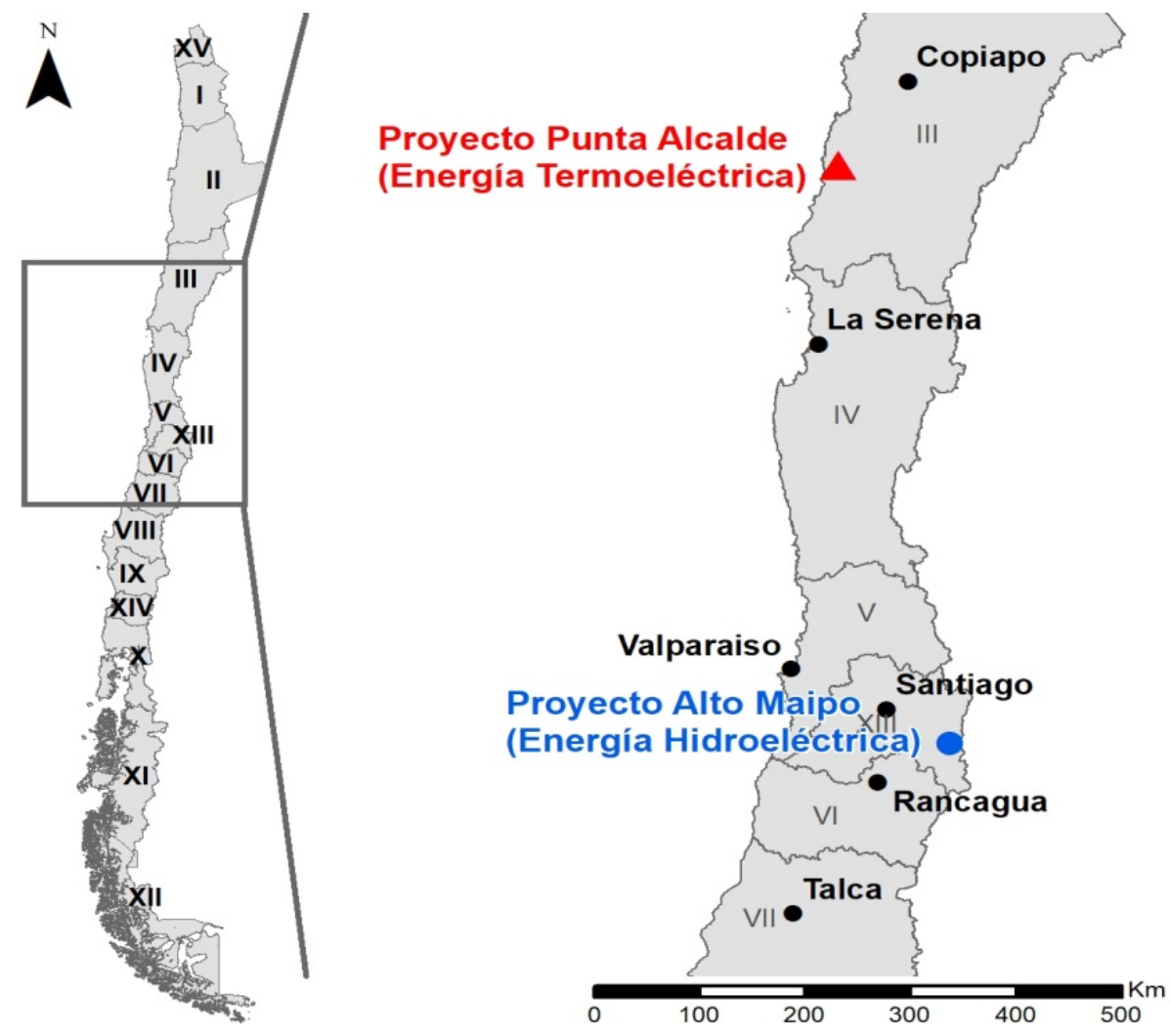

Figura 1. Ubicación Proyectos Punta Alcalde y Alto Maipo.

Con bases en esta afirmación, se propone como objetivo un doble desafío: por un lado, generar información empírica sobre dos conflictos socioambientales y su incidencia política en el territorio; y, por otro, identificar el mecanismo causal que vincula un conflicto socio-ambiental con la generación de resultados políticos locales en tres ámbitos: agenda política, institucionalidad y liderazgos políticos.

El artículo se presenta de la siguiente forma. Primero se señala la aproximación teórica a la investigación, la cual considera el conflicto socioambiental y los movimientos sociales desde la perspectiva de los resultados políticos. Con ello se busca mostrar el marco analítico del relato, con el fin de dar paso a la segunda parte, que consiste en la presentación empírica de los casos de estudio. Finalmente, se concluye señalando que los conflictos generan resultados políticos en los territorios cuando sobrepasan el ámbito ambiental para constituirse como socioterritoriales; es decir, cuando se ponen en juego los mecanismos del poder y las relaciones de fuerza entre los actores sociales, y no solo cuando se demanda acciones en contra de los proyectos específicos.

En primer lugar, se entenderá el carácter socioambiental del conflicto como una forma de concebir la posición y narrativa históricas, en la cual procesos sociales, territoriales $\mathrm{y}$ 
Cortez López, M. A. (2019). Resultados políticos de los conflictos socio ambientales eléctricos en Chile. Revista de Sociologia, 34(1), 102-121. doi: 10.5354/0719-529X.2019.54266

ambientales se vinculan a través de espacios de controversias y disputas en el largo plazo, "que tiende a hacerse tradicional o normal" (Folchi, 2001, p. 91). La dimensión de conflictividad surgirá a partir de la disputa por recursos naturales, tanto en sus dimensiones materiales como simbólicas en un territorio específico dado. En términos teóricos, los conflictos socioambientales han sido abordados ampliamente en cuanto a sus causas y trayectorias por la ecología política y la geografía, relacionándose fundamentalmente con la distribución de costos ambientales en el territorio. A este respecto, se ha demostrado que existe una clara relación entre desigualdad, pobreza y costos ambientales asociados a los sectores excluidos de la población (Bebbington \& Humphreys, 2009). Asimismo, se ha profundizado en aspectos relativos a la experiencia social de estos impactos, a través de sufrimiento ambiental ocasionado en el territorio (Auyero \& Swistun, 2007). En estos conflictos, por otra parte, se aprecia una notoria ausencia de mecanismos institucionales para procesarlos, así como poca participación de partidos políticos tradicionales (Medel \& Somma, 2016), por lo que se optará por una mirada propia sobre el territorio en función de estas coordenadas contemporáneas, que ponga de relieve el resultado político por sobre las causas de los conflictos, los movimientos sociales tradicionales o las consecuencias exclusivamente ambientales. Usualmente, este tipo de conflictos involucra a una gran diversidad de actores que participan de movimientos sociales y que, a su vez, pueden articularse como coaliciones o redes. Estado, empresas, comunidades indígenas y no indígenas, entre otros, deben sumarse a este espacio de controversias socio-ambientales y políticas. Estos conflictos socio-ambientales surgen a partir de la oposición a un proyecto de inversión específico, generando un movimiento social que tiene como objetivo la reclamación por los daños generados por dicho proyecto, lo cual los distingue de otro tipo de conflictos y movilizaciones estudiados tradicionalmente en ciencia política o sociología política (como por ejemplo los movimientos obreros o indigenistas). En este sentido, los movimientos sociales se pueden entender como "redes de interacción informal entre una pluralidad de individuos, grupos y/o organizaciones, envueltos en un conflicto político y/o cultural, sobre la base de una identidad colectiva compartida" (Diani, 1992, p. 3). Las diversas aproximaciones teóricas sobre los movimientos sociales coinciden en su carácter flexible, que se define por buscar la generación de cambios en la estructura social, distribución de recompensas, creencias compartidas y liderazgos capaces de llevar esas creencias a la práctica; en este nivel, lo fundamental es que actores excluidos buscan participar del sistema político (Diani, 2015). Por otra parte, la relación de los movimientos sociales con los conflictos socio-ambientales se ha dado tradicionalmente desde su conexión con partidos y oportunidades políticas; sin embargo, en las últimas décadas ha habido un proceso de autonomización de los movimientos con respecto a identidades, ideologías e incluso modelos específicos de desarrollo.

Esta autonomización de los movimientos sociales con respecto al aparato institucional facilita el 
Cortez López, M. A. (2019). Resultados políticos de los conflictos socio ambientales eléctricos en Chile. Revista de Sociologia, 34(1), 102-121. doi: 10.5354/0719-529X.2019.54266

empleo de tácticas disruptivas, así como la emergencia de movimientos ciudadanos (Donoso \& von Bülow, 2017) que se definen, precisamente, por su distancia con respecto a las dinámicas de los partidos políticos, así como por las ideologías que los sostienen.

La literatura específica sobre resultados políticos señala que los principales elementos vinculados en estos fenómenos se relacionan con movimientos sociales que inciden en los procesos políticos institucionales y la construcción de agendas, en áreas tan diversas como los derechos cívicos, procesos electorales, burocracias estatales, liderazgos, entre otros (Amenta et al., 2010). Esta incidencia se da en contextos más amplios de oportunidades políticas y estrategias, que pueden terminar afectando desde la futura elección de autoridades locales hasta políticas públicas a nivel nacional (Bosi \& Uba, 2009). Esta variedad de posibilidades tiene como elementos comunes la búsqueda de control de la agenda, así como eventuales transformaciones institucionales que den viabilidad a las demandas de los movimientos sociales y otros actores presentes en el conflicto. En este punto, la información empírica levantada en este estudio alude fundamentalmente a la construcción de una agenda ambiental y luego territorial; a una institucionalidad que responde a esta nueva agenda y a liderazgos que la dirigen. En este sentido es que se puede hablar de la construcción política del territorio.

De acuerdo a lo señalado por Petrone (2009), la agenda política puede ser entendida como el listado de asuntos políticos importantes, es decir, aquellos a los cuales se les presta atención por parte de los tomadores de decisión al interior del sistema político (en sus distintas escalas). Su vínculo con los conflictos socio-ambientales, por tanto, es evidente: los movimientos sociales expresarán sus demandas en el espacio público, las cuales podrían llegar a convertirse en un asunto de la agenda. En este sentido, no es extraño que uno de los principales resultados políticos de un conflicto sea precisamente su incidencia en la agenda política.

$\mathrm{Si}$ bien, en los conflictos estudiados los movimientos sociales logran instalar la agenda ambiental, esta paulatinamente desborda ese espacio para abarcar distintas dimensiones del territorio, tales como salud, educación, empleo, ordenamiento, etc. Resulta importante, entonces, ampliar la mirada socio-ambiental de los conflictos y articular paulatinamente una concepción teórica que aluda más bien a conflictos socio-territoriales, en términos de una relación más compleja de objetivos y actores en disputa.

Según señala Altschuler (2013), el territorio no es un espacio físico ni tampoco una construcción socio-cultural (simbólica) estática, sino que debe entenderse como un conjunto de escenarios multidimensionales en permanente transformación. Un elemento central es que el territorio se encuentra anclado en torno a un espacio geográfico, lo cual lo distingue de la esfera política nacional o transnacional, las cuales no presentan esta conexión territorial. La dimensión política del territorio comienza a ser tomada en consideración a partir de la década de 1970, por la geografía crítica y la ecología política. Esto se logra fundamentalmente desde 
la perspectiva del modelo extractivista (Gudynas, 2015), para la cual el territorio pasaría a ser un espacio que, en su definición, funciones, alcances y dispositivos, estaría en permanente tensión por parte de los actores sociales, convirtiéndolo en un asunto de territorialidades, en el sentido de la posibilidad de construir social y políticamente distintos territorios en un espacio geográfico. Estos dispositivos políticos fundamentalmente agendas, institucionalidad y liderazgos, se dan en el marco de una dimensión narrativa neoliberal, dando por sentado una ontología del territorio (Escobar, 2014) que no se problematiza en términos ideológicos, por lo que el extractivismo y el neoliberalismo terminan por imponerse como visión de mundo a escala local.

\section{MÉTODO}

La metodología usada en esta investigación fue cualitativa y de carácter descriptivo, entendiendo que los fenómenos sociales son construcciones sociales elaboradas por los sujetos a partir de sus discursos y prácticas (Quecedo \& Castaño, 2002). En este sentido, se ha pretendido caracterizar un proceso sociocultural y político complejo a partir de dos estudios de caso construidos a partir de los relatos de los sujetos que protagonizaron los conflictos analizados.

Las técnicas utilizadas fueron entrevistas semiestructuradas (entre los años 2016 y 2017); observación directa de puntos claves del escenario territorial del conflicto; y análisis de documentos, tanto de los proyectos como los correspondientes a los planes de ordenamiento territorial (tales como planes de desarrollo comunal y planos reguladores). De esta manera, se buscó triangular la información obtenida a través del trabajo de campo (Guber, 2001) donde, caminar junto a los entrevistados, observando el mar y el desierto, facilita la comprensión práctica del impacto de ser una zona de sacrificio.

$\mathrm{El}$ análisis realizado sigue la lógica del análisis de discurso (Santander, 2011), que busca obtener unidades mínimas de significación a partir de las dos dimensiones del estudio: i) agenda y nueva institucionalidad; y ii) liderazgos políticos. Estas dimensiones surgen tanto de la revisión teórica de literatura especializada sobre conflictos socioambientales, como de la producción empírica, con un especial énfasis en este último polo. La operacionalización de estas dimensiones consideró la identificación de actores sociopolíticos, representaciones sociales, momentos históricos clave y decisiones políticas relevantes en el marco de los dos conflictos estudiados. La selección de los entrevistados responde a dos criterios: i) ser un líder o dirigente social con participación activa durante el conflicto; y ii) ser un actor social con gran conocimiento sobre el territorio y el conflicto, aún no cuando no tuviese participación directa en el conflicto. 
Cortez López, M. A. (2019). Resultados políticos de los conflictos socio ambientales eléctricos en Chile. Revista de Sociologia, 34(1), 102-121. doi: 10.5354/0719-529X.2019.54266

Para el caso de las entrevistas, éstas fueron grabadas y posteriormente transcritas. Se utilizaron criterios etnográficos para realizarlas, centradas en el desarrollo de confianza y apertura por parte de los entrevistados y las entrevistadas. La observación, en tanto, se enfocó en elementos de contexto como por ejemplo sectores poblados, vialidad, sectores industriales, entre otros, así como en otros elementos dirigidos por los propios entrevistados(as), principalmente, sitios de protesta y lugares de afectación ambiental. En este sentido, los lugares en donde las protestas fueron realizadas, según se pudo observar en terreno, recuperaron el tránsito cotidiano que alguna vez fue puesto en tensión por los movimientos sociales. Por último, la información secundaria permitió dar un marco interpretativo temporal y territorial a las entrevistas realizadas.

El análisis de las entrevistas se realizó en función de las dimensiones de análisis planteadas en la investigación: agenda, institucionalidad y liderazgo. No obstante, diversos elementos emergentes contribuyeron a profundizar en estos elementos, sobre todo los provenientes de la memoria social y el imaginario territorial de las personas entrevistadas.

En términos éticos, se ha resguardado la identidad de las personas entrevistadas, por la propia naturaleza conflictiva del proceso en el que se encuentran involucrados. De igual forma, se tuvo en cuenta la devolución de los resultados a quienes estuvieran interesados. Esta devolución se realizó tanto en la comuna de
Huasco como en San José de Maipo, mediante la presentación de los resultados del estudio a los sujetos entrevistados.

Los casos seleccionados corresponden a los conflictos socio-territoriales derivados de los mega proyectos central termoeléctrica Punta Alcalde, ubicada en la comuna de Huasco, Región de Atacama, y el proyecto hidroeléctrico Alto Maipo, en la comuna de San José de Maipo, Región Metropolitana.

La situación actual de ambos conflictos se encuentra en etapas distintas: mientras la central termoeléctrica Punta Alcalde está en la actualidad detenida indefinidamente, el proyecto hidroeléctrico Alto Maipo se está construyendo en medio de diversas controversias sociales y jurídicas.

Se propuso una aproximación metodológica compuesta por la aplicación del método etnográfico, caracterizado por la descripción de significados sociales (Geertz, 1973). De manera complementaria se utilizó el process tracing, proveniente de la ciencia política, que apunta a construir narrativas complejas que den cuenta de causalidades dentro de estudios de caso (Bril, Maillet \& Mayaux, 2017). Para esta aproximación metodológica, procesos, secuencias y coyunturas se vuelven elementos clave del análisis (Bennett \& Checkel, 2014).

Las causalidades que busca identificar el process tracing se construyen a partir de la permanente iteración entre hipótesis y producción de datos empíricos. En este estudio, la hipótesis inicial establece que la oposición a cada uno de los proyectos fue la causa de los resultados políticos; sin embargo, fue necesario probar hipótesis 
Cortez López, M. A. (2019). Resultados políticos de los conflictos socio ambientales eléctricos en Chile. Revista de Sociologia, 34(1), 102-121. doi: 10.5354/0719-529X.2019.54266

alternativas a partir de los datos y la trayectoria del conflicto, con el fin de determinar que esta causa fuera necesaria y suficiente para las consecuencias estudiadas. Los resultados de este estudio están planteados como un relato que simplifique estas iteraciones a partir de solo un hilo conductor.

Sobre la selección de los casos, se puede mencionar similitudes y diferencias. Por un lado ambos proyectos comparten un elevado monto de inversión inicial. Por otro, difieren en su resultado inmediato; es decir, en la incidencia aparente sobre la construcción de la central: en el primer caso la empresa desistió, mientras en el otro se está construyendo. También difieren en la articulación que tienen con otros conflictos del mismo orden, ya que el conflicto causado por el proyecto de central Punta Alcalde se desarrolla en un territorio donde han ocurrido otros en años anteriores, en torno a la minería, como el caso de Pascua-Lama; el agro-negocio, como el caso de Freirina; o la misma industria eléctrica, como el caso de Central Castilla. Así, los dos conflictos presentan diferencias importantes, pero, como veremos, consecuencias relativamente parecidas en ciertas áreas.

Para el caso de la termoeléctrica Punta Alcalde, se llevaron a cabo dos campañas de terreno en la comuna de Huasco: la primera entre los días 7 y 12 de noviembre de 2016, con el fin de explorar y levantar información primaria que permitiera definir los alcances del caso, sus protagonistas, hitos y situaciones clave; y la segunda entre el 16 y 21 de enero de 2017, cuyo propósito fue registrar evidencia faltante y poner a prueba algunas hipótesis de trabajo.

Para el caso Alto Maipo, se llevó a cabo una campaña de terreno entre los días 23 de noviembre y 24 de enero en la comuna de San José de Maipo, con un total de 10 visitas a terreno y 16 entrevistas, con el fin de explorar y levantar información primaria que permitiera definir los alcances del caso, sus protagonistas, hitos y situaciones clave. A continuación se desarrolla el relato causal de cada uno de los casos.

\section{RESULTADOS}

Agenda y nueva institucionalidad

En el caso del proyecto termoeléctrico Punta Alcalde, ocurrió un proceso de transformación en la agenda política entre los años 2012 y 2017 . El origen de este conflicto socio-ambiental se encuentra en el quiebre de esta agenda, toda vez que los alcaldes electos a nivel local y regional se históricamente apoyaban la generación de empleo a toda costa, invisibilizando otras áreas de desarrollo -entre ellas la ambiental. Los proyectos de inversión, principalmente mineros, eran la prioridad en toda la región desde el punto de vista de la agenda política. En el caso específico de la comuna de Huasco, predominaba la protección al empleo brindado por la compañía CAP Minería, que sustenta históricamente a esta comuna en términos de empleabilidad. Este 
pacto se rompió en 2012 a raíz de la afectación generada por la empresa Agrosuper en la comuna de Freirina, ubicada a pocos kilómetros de Huasco; ésta emitía fuertes olores en un amplio radio, que se percibían incluso en las comunas de Huasco y Vallenar, ubicadas a 16 y $34 \mathrm{~km}$., respectivamente.

En este sentido, un entrevistado sostiene que:

"A la hora de colación los niños vomitaban, no querían comer, no querían almuerzo, no querían colación, no querían nada porque les daba vómito. Entonces había que cerrar ventanas. Nos llenábamos de moscas, además los olores. Imagínate nosotros que recibíamos un impacto fuerte, cómo serían ellos [Freirina] [...] Se hizo una asamblea, se hizo un movimiento social de conversación diaria con la gente. Había un lugar de encuentro permanente donde no habían líderes evidentes" (Hombre, 36 años).

Las primeras molestias y demandas a autoridades en la comuna de Freirina comenzaron a generar alianzas con algunos dirigentes sociales de Huasco, ligados a la iglesia católica como a madres de niños con enfermedades respiratorias, lo cual permitió rearticular liderazgos ambientales que habían estado operativos desde el año 2005 a raíz del conflicto generado por la compañía minera Barrick Gold a través de su Proyecto Pascua Lama, ubicado en el mismo valle en la zona precordillerana. Además, existía el precedente en la región de la protesta en contra del proyecto termoeléctrico Central Castilla el año 2010, momento en que los habitantes de Huasco pudieron observar que un proyecto podría ser detenido si la comunidad lograba mostrar oposición. Este punto es relevante puesto que el tipo de producción de energía termoeléctrica, es considerada como de alto impacto negativo en términos socio-ambientales, específicamente para la salud humana.

Las visitas de autoridades políticas durante el conflicto de Agrosuper fueron inmediatamente percibidas como negativas por parte de la comunidad organizada, debido al carácter "ciudadano" que los líderes sociales quisieron darle a las protestas; de acuerdo a esto, "ningún político [era] bienvenido", según señala un entrevistado. En este contexto de movilización, se incorporó en uno de los petitorios a la autoridad la cancelación del proyecto Punta Alcalde, ubicado en la vecina comuna de Huasco. De este modo, apareció por primera vez la oposición a este proyecto como una demanda social formal, en términos de una agenda pública específica. Este petitorio se realizó en 2012, aun cuando las molestias en relación a Punta Alcalde se venían expresando ya desde 2010. En este momento el único partido político vinculado a las protestas era el Partido Comunista, el cual contaba con un vocero al interior del movimiento contra Agrosuper proveniente de la comuna de Huasco, y que sería, posteriormente, líder social y político en contra de Punta Alcalde.

En términos medioambientales, los dirigentes sociales y políticos locales del movimiento social, llegaron a la conclusión que la legislación es débil y "pro empresas", externalizando los costos hacia los territorios y las comunidades. Esto, debido a que el impacto acumulado entre proyectos, no es medido en la legislación ambiental (como la ley 
Cortez López, M. A. (2019). Resultados políticos de los conflictos socio ambientales eléctricos en Chile. Revista de Sociologia, 34(1), 102-121. doi: 10.5354/0719-529X.2019.54266

19.300 de Bases del Medio Ambiente); por tanto, no se evaluaría correctamente el impacto real sobre la salud de las personas ni sobre el ecosistema. Se da origen así a una definición territorial denominada "zona de sacrificio", entendido como un espacio geográfico que soporta un exceso de carga contaminante. De este modo, son los actores políticos locales quienes dirigieron las movilizaciones al margen de partidos políticos o autoridades formales.

El sentido más profundo del término medioambiental, se puede apreciar en el relato de un habitante de Huasco:

"Aquí el tema principal es el de la salud, aquí no hay un tema económico [...] Nuestro propósito era defender la vida y la salud de las personas de Huasco" (Hombre, 35 años).

De forma paralela, desde 2015, se llevó a cabo, a través del Ministerio de Medioambiente, el programa de recuperación ambiental y social, en virtud del cual se conformó una mesa de trabajo denominada Consejo para la Recuperación Ambiental y Social de Huasco (CRAS). Esta mesa se integró por autoridades públicas, empresas con representantes de nivel gerencial y la comunidad. Sin embargo, desde la comunidad se tendía a desconfiar del carácter no-vinculante de la instancia, prefiriendo muchos actores locales mantenerse articulados como una red-ciudadana en torno a otras zonas de sacrificio o localidades con problemáticas socio-ambientales. Por otra parte, al interior del CRAS se generó un desequilibrio de información y capacidades técnicas, por cuanto los integrantes del Estado y de las compañías poseían un nivel técnico superior al de la comunidad, lo cual era percibido por los dirigentes sociales locales como un desbalance en los dispositivos del ejercicio de poder.

Para el caso del proyecto hidroeléctrico Alto Maipo, el conflicto surgió a propósito de las reuniones de participación ciudadana en 2007, en el marco del estudio de impacto ambiental del mismo. En este periodo se realizaron reuniones de vecinos y apoderados en el Colegio Andino, ubicado en el sector de El Manzano. En este momento comenzó a formarse un grupo organizado y contrario al proyecto, que desplegó un conjunto de acciones para establecerse como contraparte válida en el estudio de impacto ambiental; de este modo, la labor técnica e institucional, fundamentalmente en torno al Estudio de Impacto Ambiental, comenzó a ocupar un lugar central. Surgió entonces la principal organización vinculada a la oposición al proyecto, la "Coordinadora No Alto Maipo".

En términos de la agenda local, históricamente predominaba una preocupación por el desempleo en la zona. Sin embargo, a partir del conflicto, la movilización social logró instalar la agenda ambiental, sin que ninguna de las dos desapareciera, poniendo presión sobre la institucionalidad local al tensionar cesantía y medioambiente. Ante la inexistencia de un modelo de desarrollo local, estas agendas fueron apropiadas por una nueva institucionalidad para la gobernanza del territorio. En este caso, el tipo de producción de energía, hidroeléctrica, no era considerada por la población como de afectación a la salud humana, por lo cual la contaminación, propiamente tal, no fue el elemento clave de la 
Cortez López, M. A. (2019). Resultados políticos de los conflictos socio ambientales eléctricos en Chile. Revista de Sociologia, 34(1), 102-121. doi: 10.5354/0719-529X.2019.54266

agenda, sino que la disponibilidad del recurso hídrico por parte de los actores locales.

En la comuna de San José de Maipo, el dispositivo que afectó a la gobernanza estuvo liderado por la propia compañía a través del establecimiento de un Convenio Social construido a través de un proceso de diálogo entre diversos actores del territorio. En marzo de 2009 se firmó el Convenio entre la Municipalidad de San José de Maipo, la Unión Comunal de Juntas de Vecino y AES Gener S.A., el cual tiene una vigencia de 30 años, y cuyo fin es el despliegue de un proceso de diálogo y colaboración entre todas las partes en función de los intereses y necesidades locales. De este modo se establecieron las áreas del Convenio: i) educación y capacitación; ii) desarrollo social e infraestructura de uso comunitario; iii) promoción y desarrollo de actividades productivas o de servicios que generen desarrollo local; y iv) apoyo al deporte. Asimismo, se consignó que durante la etapa de construcción se contrataría a un mínimo de 500 personas provenientes de la comuna. También se consideró un fondo concursable para proyectos de beneficio social e interés colectivo.

El liderazgo, las áreas a trabajar y el manejo de los eventuales impactos a largo plazo a partir del establecimiento de este Convenio, generaron un debate implícito por parte de los actores sociales, surgiendo diversas perspectivas sobre cómo afrontar este acuerdo. Para algunos actores, la propuesta del Convenio debió haber surgido desde el municipio, y no al revés, como ocurrió, puesto que se podría afectar el carácter democrático de la decisión sobre el territorio -al menos desde la perspectiva de la democracia representativa. Otros, en tanto, han valorado la capacidad de empatizar de la compañía, puesto que pareció haber comprendido las dinámicas locales y adaptado bien a ellas. Otro grupo, finalmente, consideró que toda medida era insuficiente y negaban la legitimidad de este modelo paralelo de gobernanza. Como se puede apreciar, ante la falta de objetivos de desarrollo local, se generó un modelo de toma de decisiones complementario al del gobierno local, que definió sus propios ejes de desarrollo en torno a la educación y la empleabilidad, y cuyas fuentes de legitimidad provenían de instancias extraestatales, tales como el Banco Mundial y la Corporación Financiera Internacional -los cuales se vincularían a los territorios por medio de este tipo de instrumentos de gestión comunitaria. Este proceso de gobernanza, en términos de resultados políticos, instaló una nueva institucionalidad territorial, la cual, desde el punto de vista de dirigentes sociales locales, expresa cierta debilidad por parte del Estado.

Otro instrumento de planificación territorial fue el Acuerdo Voluntario de Gestión de Cuencas, desarrollado por el Consejo de Producción Limpia (CPL). En éste, las diversas instituciones del Estado se coordinarían para la protección de la cuenca del río Maipo y del río Clarillo, en la vecina comuna de Pirque. Del mismo modo como los actores locales habían sido invitados a participar de este acuerdo, también fueron convocados a discutir la ley de protección de glaciares y la modificación del código de aguas, lo cual representa un cambio en los dispositivos políticos locales, puesto que líderes sociales del 
Cortez López, M. A. (2019). Resultados políticos de los conflictos socio ambientales eléctricos en Chile. Revista de Sociologia, 34(1), 102-121. doi: 10.5354/0719-529X.2019.54266

territorio se integran a un proceso institucional en el cual no tenían participación previo al conflicto.

El conflicto socio-ambiental, que detonó el proceso de movilización a partir de la transformación de la agenda y de la construcción de una nueva institucionalidad, terminó finalmente por ampliar la mirada sobre las causas del conflicto, acercándose así a procesos de gobernanza con capacidad de decidir sobre la planificación y orientación del territorio. En este sentido, comienza a articularse la dimensión territorial por sobre la ambiental como elemento de análisis. En el marco del proceso descrito, surgen también como resultado político del conflicto los liderazgos que empujan estas transformaciones.

\section{Liderazgos}

En la comuna de Huasco, los liderazgos han sido diversos, pero han compartido una estrategia. Esta articulación de actores diversos reactiva el Consejo de Defensa del Valle del Huasco que había operado en contra del proyecto minero Pascua Lama desde el año 2005. Este proceso de reactivación aparece al mismo tiempo que comienzan las manifestaciones en contra de la empresa de alimentos Agrosuper, en términos del daño que genera en el territorio, lo cual se evidencia en el siguiente relato:

"Levantarse a las 7 de la mañana y sentir los olores de Agrosuper, era algo que vivimos toda la Provincia, no sólo se sentía en Vallenar, se sentía en Freirina, Maitencillo, Vallenar y también en Huasco. Y desde ahí se empezaron a unir polos ambientalistas de la zona que son de Huasco, para realizar un trabajo en conjunto con los ambientalistas de Agrosuper. Y de ahí también se genera estos líderes ambientalistas. También nace un alcalde ambientalista que es César Orellana [en Freirina], que milita en el Partido Socialista, pero antes de ser alcalde fue Consejero Regional, y fue uno de los principales actores del proceso ambientalista" (Hombre, 40 años). Como se puede apreciar, se instaló un imaginario en torno a la unidad territorial del valle, el cual ha atravesado diversos conflictos socioambientales durante las últimas décadas. Así surgió en la comuna la organización de carácter socio-ambiental más relevante, denominada "Brigada SOS Huasco", la cual se compuso de personas vinculadas a quienes padecieron alguna enfermedad grave a causa de vivir en una zona de sacrificio, así como de líderes formados en las juventudes cristianas de base. Es importante enfatizar que algunos de los líderes de los movimientos socioambientales de Huasco y Freirina tienen sus orígenes en la religión católica, específicamente en una corriente denominada Teología de la Liberación, lo cual permite comprender el vínculo moral del movimiento más allá del rechazo a la contaminación propiamente tal.

En este contexto, las estrategias utilizadas por el movimiento social y el repertorio de acciones actuales han sido vistas como una continuación tanto temporal como espacial de otros movimientos sociales. Temporal, puesto que se remontan a la década de 1990, a partir de la primera protesta de los olivicultores en contra de 
Cortez López, M. A. (2019). Resultados políticos de los conflictos socio ambientales eléctricos en Chile. Revista de Sociologia, 34(1), 102-121. doi: 10.5354/0719-529X.2019.54266

CAP Minería; y espacial, pues involucra a todo el valle. Estas estrategias -y esta noción espaciotemporal- entienden a los partidos políticos y a los funcionarios políticos como aceleradores de decisiones al interior del sistema político, es decir, al margen de la ciudadanía, y como distractores, a través la cooptación de las demandas del movimiento social.

Un conjunto de decisiones políticas a puertas cerradas terminó por justificar esta desconfianza, lo cual llega a su punto más alto con la aprobación del proyecto Punta Alcalde a través de un Consejo de Ministros, poniendo término a todo el proceso institucional y judicial que existía hasta durante el año 2012. En este punto, los principales aliados de este movimiento fueron las ONGs Oceana, el Observatorio Latinoamericano de Conflictos Ambientales (OLCA) y la Fundación Terram. Se estableció además contacto con casos similares de las comunas de Puchuncaví, Mejillones y Coronel, a raíz de los cuales se compartía la conciencia de ser zonas de sacrificio, y en donde se tuvo la oportunidad de "comparar realidades", recibir asesoría mutua y generar lineamientos de trabajo para acudir con planteamientos y demandas ante la Cámara de Diputados y otras autoridades.

Durante todo este proceso, el sistema político se mostró ausente del procesamiento del conflicto al no generar canales de diálogo apropiados tomando decisiones al margen de la ciudadanía -todo ello según la perspectiva de actores políticos locales. En este sentido, una entrevistada señala:
"Los partido políticos ya venía de antes de esto. Nunca se quisieron comprometer, ellos nunca quisieron colaborar" (Mujer, 60 años).

El rol del gobierno local, posteriormente, vuelve a ser central ante el triunfo del alcalde PPD Rodrigo Loyola, el año 2012, el cual instala la agenda ambiental como uno de los ejes de su trabajo, lo cual se expresa en que interpone una demanda contra el Proyecto Punta Alcalde. Cabe destacar, en este sentido, que el Alcalde Rodrigo Loyola fue reelecto el año 2016 con un $52.36 \%$ de los votos, y Daniel Díaz, candidato Independiente del Pacto Con la Fuerza del Futuro, uno de los líderes ambientalistas, es electo como Concejal con primera mayoría con un $10.47 \%$, demostrando uno de los efectos más evidentes del conflicto social. Cabe destacar, a su vez, que el alcalde de Freirina, César Orellana, del Partido Socialista, también líder del movimiento social, fue reelecto con el $55.61 \%$ de la votación.

En este escenario se crea en 2012 la organización local "Huasco Consciente", que participa dialogando con la institucionalidad, mientras que la Brigada SOS Huasco mantiene una postura más radicalizada. Esta última buscaba disminuir la presencia de líderes en el escenario público con el fin de evitar las represalias contra ellos, de modo que diversos actores sociales pueden declarar ser simpatizantes de ambas organizaciones sin estar inscrito en ninguna de las dos.

El repertorio de acciones generadas desde estos liderazgos, consideró la creación de murales, "cacerolazos", "velatones", "funas" en la radio y en actividades de relacionamiento comunitario 
Cortez López, M. A. (2019). Resultados políticos de los conflictos socio ambientales eléctricos en Chile. Revista de Sociologia, 34(1), 102-121. doi: 10.5354/0719-529X.2019.54266

de AES Gener, además de cortes de caminos. Estas actividades son apoyadas por la iglesia católica local y tuvieron un fuerte componente artístico-cultural, a través de la participación de artistas locales.

En este contexto, se puede mencionar que los principales productos del movimiento social fueron los siguientes: i) articular un movimiento social amplio e inclusivo entre las comunas de Freirina y Huasco; ii) expulsar a la empresa Agrosuper de la comuna de Freirina e impedir la instalación de Punta Alcalde; iii) instar al Decreto del territorio como zona de latencia; iv) cierre de la cuenca del río Huasco para al manejo sustentable del recurso hídrico; y v) la creación del Plan de Recuperación Social y Ambiental de Huasco (PRAS), junto con el CRAS, lo cual es señalado por la Presidenta Michelle Bachelet en el discurso del 21 de mayo. En 2012 los movimientos socio-ambientales logran obtener unas de sus victorias más relevantes: que la comuna sea declarada "zona de latencia por material particulado" (tamaño PM10). La comunidad, entonces, se percibe a sí misma como unificada y exitosa frente a los proyectos privados y frente a la institucionalidad pública.

En el caso de Alto Maipo, el liderazgo político corresponde a la Coordinadora No Alto Maipo. De manera paralela al diseño institucional que realizaban algunos actores importantes en el territorio, la Coordinadora enfrentaba procesos de frustración en su relación con el sistema político formal debido a la falta de respuestas a sus demandas. Se realizaron un conjunto de reuniones con las autoridades de diversos ministerios, secretarías e incluso el gobierno local, en donde los dirigentes locales adquieren consciencia sobre los verdaderos incentivos de los tomadores de decisión, tanto públicos como privados, como por ejemplo propiedad e industrialización del agua. El territorio, en este sentido, según señalan los entrevistados, se constituye productivamente en torno al agua y se decide en torno a él según las tres grandes actividades productivas: i) sanitaria; ii) hidroeléctrica; y iii) riego.

Una de las primeras decisiones que tomó esta agrupación consistió en acordar una negativa a negociar mitigaciones o compensaciones económicas con Alto Maipo o el Estado de Chile. En segundo lugar, se decidió que la organización sería transversal, y sin participación de ONGs o políticos. Esto, con el fin de presentar una posición frente a las autoridades y la opinión pública que diera legitimidad al movimiento, lo cual resulta interesante en términos de la interpretación que hace la Coordinadora sobre su vínculo con la institucionalidad política, en términos de la desconfianza que existe hacia el Estado. Asimismo, se acuerda no aceptar "intromisiones" de actores que decidan a nombre de la asamblea, tales como la priorización de temas o la designación de voceros, como habría ocurrido en el caso del proyecto hidroeléctrico Hidroaysén el proyecto minero Pascua Lama; en estos casos, se señala que algunas ONGs adquirieron "demasiado" protagonismo, llegando a liderar el proceso en desmedro de la propia comunidad local.

No obstante lo anterior, la Coordinadora recibió apoyo de organizaciones ambientales con experiencia y conocimiento técnico-político, tales 
Cortez López, M. A. (2019). Resultados políticos de los conflictos socio ambientales eléctricos en Chile. Revista de Sociologia, 34(1), 102-121. doi: 10.5354/0719-529X.2019.54266

como la ONG Ecosistemas, Fundación Terram, Oceana, Chile Sustentable y el OLCA. Este apoyo les sirvió para entender con mayor profundidad el sistema institucional chileno y generar reuniones con ministros $y$ parlamentarios, además de acceder a preparación en materia medioambiental, legal y política. La intención del movimiento social fue formar una coordinadora ciudadana con la capacidad de sumar a otras organizaciones de acuerdo al clima político del momento, es decir, que fuera capaz de sumar activistas de todo el espectro político e ideológico. $\mathrm{Al}$ respecto, una de las fundadoras del movimiento social señala que esta forma organizativa tiene como referente directo el movimiento estudiantil ocurrido en Chile el año 2011, lo cual es relevante debido a la forma en que se construyen los liderazgos, en donde las vocerías reemplazan a las dirigencias. Dada esta diversidad de actores, es posible reconocer variados discursos sociales acerca de la oposición tanto al modelo extractivista como al Estado y al propio proyecto. Según señalan los entrevistados, entre estos opositores se cuentan empresarios turísticos que podrían ver afectados sus negocios; pobladores que ven alterada su vida cotidiana; personas en desacuerdo con el modelo de desarrollo por causa de la usurpación de recursos naturales por parte de las transnacionales; y habitantes en defensa del río. Existe también un discurso transversal que ve en Alto Maipo una expresión más del abuso de la elite político-empresarial, que se percibe ejerciendo abusos igualmente en los ámbitos de la educación, salud, etc. El objetivo transversal, entonces, es expresar esta oposición en términos de "No Alto Maipo".

En todos los casos se puede apreciar la existencia de una coalición de actores unidos en torno a los objetivos específicos "No a Punta Alcalde" y "No a Alto Maipo", en la que participa un conjunto diferenciado de actores sociales y políticos, que poseen recursos, capacidades y canales de acción diferenciados. Su expresión institucional cuenta con la concejal PPD Maite Birke, que apoya la agenda ambiental, pero que no constituye un liderazgo con capacidad de generar movimientos sociales ni de reemplazar a la Coordinadora, según señalan los entrevistados, debido a su estrecho vínculo con un partido político. No obstante, se evidencia que el camino político institucional es validado en el marco del conflicto, así como la búsqueda de apoyo técnico para dialogar con el resto de los actores, lo cual se puede evidenciar en el permanente diálogo entre dirigentes locales y alcaldía, así como reuniones con diputados y senadores comunales, provinciales y regionales. Esta búsqueda de diálogo generada desde la comunidad a través del aprendizaje de otros lenguajes (técnico y político), es complementada con repertorios de protesta complementarios a los canales formales de expresión política, sobre lo que profundizaremos a continuación.

El repertorio de acciones de protesta, en este escenario, tiene como correlato las tensiones dentro de las propias organizaciones locales. Comenzó con dos organizaciones opositoras a Alto Maipo: la Coordinadora en Defensa de los Ríos y la Coordinadora No Alto Maipo, la cual permanece con mayor visibilidad y vigencia. 
Esta segunda organización sufrió una división interna a partir de la cual se formó la Red Metropolitana No Alto Maipo. Al margen de estas organizaciones actúan vecinos de San José de Maipo que desde sus conocimientos específicos en ingeniería, medioambiente y comunicaciones, también contribuyen con la oposición al Proyecto.

Esta oposición de carácter técnico, se puede apreciar en la siguiente cita:

"Les propusimos dos cosas, y se las propusimos con documentos y todo, no solamente con palabras: mejorar la energía de las cuatro centrales que ellos ya tienen acá, que de verdad son centrales de paso, y también después, que nos dijeron no... Y después le propusimos pequeñas centrales en los nacimientos de los ríos, donde ellos tienen sus derechos de agua. Pero con una serie de pequeñas centrales en la alta cordillera que tomaran el agua, la tomara la otra... y así... para generar un impacto menor" (Mujer, 43 años).

De este modo, el repertorio de protesta estuvo compuesto por diversas medidas, tales como las siguientes:

i) formar una coordinadora y no una organización, debido a que permite la participación de diversos actores sin la necesidad de tener estatutos o procesos de inscripción.; ii) tener vocerías, las cuales permiten que no existan liderazgos únicos"; iii) priorizar la vía pacífica, técnica y judicial por sobre la vía violenta; iv) formar redes transnacionales de apoyo con organismos medioambientales norteamericanos; vii) encarecer el proyecto buscando retrasar todos sus procesos, fundamentalmente a través de vías judiciales; viii) participación en medios de comunicación como CNN, radios y diario La Nación; expresando sus demandas y argumentos técnicos medioambientales para detener el proyecto. y ix) planteamientos de demandas ante financistas del proyecto. La instancia principal se realizó el año 2015 en Whashington, frente al Banco Mundial y el Banco Interamericano de Desarrollo, entre otros organismos financistas como la Corporación Financiera Internacional.

Síntesis de los casos

Se puede observar en el ámbito de agenda e institucionalidad, que en ambos casos se logró instalar la agenda ambiental como eje en la toma de decisiones. En el caso de la comuna de Huasco, el Plan de Recuperación Ambiental y Social definió el rumbo local, en donde se abordaron diversos ejes de desarrollo de la comuna. Para San José de Maipo, la agenda ambiental también logra instalarse, aunque de manera más débil. La institucionalidad para el desarrollo territorial fue articulada desde la propia compañía AES Gener, incorporando al resto de los actores a través de un Convenio Social. En ambos casos, se pueden observar tensiones en cuanto a la legitimidad de la nueva institucionalidad, debido a la desconfianza hacia el Estado y las grandes compañías por parte de la comunidad. Asimismo, se puede apreciar que el conflicto logró modificar el territorio a nivel de su planificación de manera relativamente permanente debido a que la toma de decisiones salió de la institucionalidad 
Cortez López, M. A. (2019). Resultados políticos de los conflictos socio ambientales eléctricos en Chile. Revista de Sociologia, 34(1), 102-121. doi: 10.5354/0719-529X.2019.54266

política formal hacia instituciones creadas a partir del conflicto.

En el ámbito de liderazgos, se aprecia, en el caso de la comuna de Huasco, que organizaciones con objetivos claros y orgánicas definidas compartieron espacios de protesta con instituciones formales como la Iglesia Católica, así como con coaliciones de actores vinculadas a todo el territorio del valle de Huasco. Estos movimientos de carácter ciudadano, al igual que en la comuna de San José de Maipo, se mantuvieron en general separados de los partidos políticos, y generaron cierta independencia con respecto a ONGs ambientalistas. Los liderazgos fueron claramente definidos en ambos casos, y generaron dinámicas variables de incidencia política, tanto institucionales (concejales, alcaldes, organizaciones de base, etc.) como extra-institucionales de carácter no-violento, centrados en el corte de caminos y manifestaciones culturales.

\section{DISCUSIÓN Y CONCLUSIONES}

La productividad política de los conflictos socioambientales es un espacio teórico y empírico poco explorado por la investigación en Chile. Si bien existen aproximaciones sobre los resultados que los conflictos generan a nivel de agendas, instituciones y políticas públicas, las transformaciones políticas a nivel territorial son aún un escenario por explorar, considerando que tanto los movimientos sociales como las políticas empresariales son cada vez más estratégicas y de largo plazo.

A partir de esta mirada sobre los conflictos, se generó evidencia empírica en torno a dos conflictos de la industria eléctrica que tuvieron gran impacto en la opinión pública nacional. Estos casos fueron la termoeléctrica Punta Alcalde, en la comuna de Huasco, y la hidroeléctrica Alto Maipo, en San José de Maipo. La descripción y análisis comparado de los casos permiten sostener que existe correlación entre el paso de un conflicto socio-ambiental a uno socioterritorial, y el aumento de productividad política del conflicto en el territorio. Esto quiere decir que cuando el conflicto desborda el ámbito puramente ambiental (asociado a los impactos negativos del proyecto sobre el medioambiente), para situarse en variadas áreas del territorio, entonces surgen trayectorias locales que promueven los resultados específicamente políticos. La evidencia mostró, en este sentido, que los principales ámbitos de productividad fueron la agenda política, el diseño de una nueva institucionalidad territorial y el surgimiento de liderazgos políticos, tanto individuales como a través de organizaciones y coaliciones.

Estas dimensiones son las que finalmente explican las dos ideas centrales del argumento. Por un lado, son las causantes de la producción de resultados políticos en el territorio y, por otro, escalan de lo socio-ambiental a lo socioterritorial. Esto se debe a que la agenda, la institucionalidad y los liderazgos son elementos o mecanismos claves del diseño del territorio, por sobre otros potenciales mecanismos como el 
sistema electoral o el ciclo de políticas públicas, los cuales no operan a nivel de diseño propiamente tal ni tampoco son intervenidos en el escenario del conflicto, debido a su carácter estructural del sistema político, por tanto más estable; y debido a que opera a nivel nacional y no local, por lo cual es más difícil que se vea impactado por la dinámica de la conflictividad socio-territorial.

De este modo, se puede señalar que las dimensiones mencionadas, así como el carácter socio-territorial del conflicto, son dos de los factores necesarios en la producción de resultados políticos a nivel local. Este carácter socio-territorial del conflicto se fundamenta en el cambio en la relación de fuerzas políticas a escala territorial, así como en una mirada más amplia y de largo plazo sobre las dinámicas locales, en comparación con las demandas específicas medioambientales sobre los proyectos eléctricos específicos. La agenda ambiental y luego territorial; la conformación de mesas de trabajo multi-actor diseñada para el desarrollo local y no específicamente para los conflictos; y la formación de liderazgos articuladores, autónomos al sistema político, son sin duda los elementos claves que dan cuenta de este proceso de transformación del territorio a partir de la productividad política del conflicto.

En relación a la agenda e institucionalidad, en este sentido, se puede apreciar el tránsito desde una cierta ambigüedad con respecto al área ambiental, hacia variadas expresiones concretas, asociadas a planes de gobernanza en el caso de la comuna de Huasco, y de gestión de recursos naturales, en el caso de San José de Maipo. Agenda e institucionalidad sólo fueron posibles de manera conjunta, dando soporte y dirección a los resultados políticos.

Los liderazgos, de manera complementaria, funcionaron a partir de la construcción de dos caminos: el institucional, que considera a alcaldes y concejales, y el extra-institucional, que se extiende a movimientos sociales, vocerías y coaliciones, otorgando la flexibilidad necesaria para que la agenda y la institucionalidad se pudiese mantener en el tiempo. Estas características podrían sin duda generalizarse para ser evaluadas en otros casos similares.

Las consecuencias sobre el diseño territorial local; la calidad de la democracia; los procesos de descentralización y de diálogo entre distintos actores locales; todos ellos son ámbitos necesarios de investigar en una agenda futura sobre conflictividad socio-ambiental y/o socioterritorial, más allá de los impactos específicos sobre el medioambiente. Asimismo, existe un espacio inter-disciplinario tanto teórico como metodológico, que puede ser abordado para dar cuenta de este tipo de fenómenos. En este estudio, se utilizaron elementos de la antropología y la ciencia política, sin embargo, existen diversos fenómenos que pueden ser abordados desde las herramientas que le son propias a la sociología, la economía y la geografía humana, y que podrían utilizarse para comprender aspectos que no se profundizaron en este estudio. 
Cortez López, M. A. (2019). Resultados políticos de los conflictos socio ambientales eléctricos en Chile. Revista de Sociologia, 34(1), 102-121. doi: 10.5354/0719-529X.2019.54266

\section{REFERENCIAS}

Aliste, E. \& Stamm, C. (2014). El aporte de un enfoque territorial al estudio de los conflictos socio-ambientales. Revista Faro, 2(20), 6678.

Altschuler, B. (2013). Territorio y desarrollo: aportes de la geografía y otras disciplinas para repensarlos. Revista Theomai, 27(1), 64-79.

Amenta, E., Care, N., Chiarello, E., \& Sum Y. (2010). The political consequences of Social movements. Annual Review of Sociology, 31(1), 287-307. doi: 10.1146/annurev- soc $^{-}$ 070308-120029

Auyero, J. \& Swistun, D. (2007). Expuestos y confundidos. Un relato etnográfico sobre sufrimiento ambiental. Revista Iconos, 28(1), 137-152. doi: 10.17141/iconos.28.2007.216

Bebbington, A. \& Humphreys, D. (2009). Actores y ambientalismos: conflictos socioambientales en Perú. Iconos Revista de Ciencias Sociales, 35(1), 117-128. doi: 10.17141/iconos.35.2009.371

Bennett, A. \& Checkel, J. (2014). Process tracing in the social sciences. From metaphor to analytic tool. Cambridge: Cambridge University Press.

Bosi, L. \& Uba, K. (2009). Introduction: The outcomes of social movements. Mobilization An International Quarterly, 14(4), 409-415.

Bowen, S., Fábrega, F., \& Medel, R. (2012). Movimientos sociales rurales y problemática medioambiental: la disputa por la territorialidad. Revista Psicoperspetivas. Individuo y Sociedad, 11(1), 204-225. doi: 10.5027/psicoperspectivas`vol11-issue1fulltext- 187

Bril, T., Maillet, A., \& Mayaux, P. (2017). Process tracing: Inducción, deducción e inferencia causal. Revista de Ciencia Política, 37(3),
277-300. doi: 10.4067/S0718090X2017000300659

Correa, H., \& Rodríguez, I. (Eds.). (2005). Encrucijadas ambientales en América Latina. Entre el manejo y la transformación de conflictos por recursos naturales. San José: Universidad para la Paz,ONU.

Delamaza, G., Maillet, A., \& Martínez, C. (2017). Socio-Territorial Conflicts in Chile: Configuration and Politicization (20052014). European Review of Latin America and Caribbean Studies, 104(1), 23-46. doi: 10.18352/erlacs. 10173

Diani, M. (1992). The concept of social movement. The Sociological Review, 40(1), 1-25. doi: 10.1111/j.1467954X.1992.tb02943.x

Diani, M. (2015). Revisando el concepto de movimiento social. Revista Encrucijadas, $9(1), 1-16$.

Donoso, S. \& Von Bülow, M (Eds.). (2017). Social Movements in Chile. Organization, Trajectories, and Political Consequences. Nueva York: Palgrave Macmillan.

Escobar, A. (2014). Sentirpensar con la tierra: Nuevas lecturas sobre desarrollo, territorio y diferencia. Medellín: CLACSO.

Folchi, M. (2001). Conflictos de contenido ambiental y ecologismo de los pobres: no siempre pobres, ni siempre ecologistas. Ecología Política, 22, 79-101.

Geertz C. (1973). La interpretación de las culturas. Barcelona: Gedisa.

Guber, R. (2001). Etnografía. Método, campo y reflexividad. Buenos Aires: Norma.

Gudynas, E. (2015). Extractivismos. Ecología, economía y política de un modo de entender el desarrollo y la naturaleza. Cochabama: CEDIB.

Instituto Nacional de Derechos Humanos (2018). Mapa de conflictos socio ambientales 
Cortez López, M. A. (2019). Resultados políticos de los conflictos socio ambientales eléctricos en Chile. Revista de Sociologia, 34(1), 102-121. doi: 10.5354/0719-529X.2019.54266

en Chile. Disponible en https://mapaconflictos.indh.cl

Medel, R. \& Somma, N. (2016). ¿Marchas, ocupaciones o barricadas? Explorando los determinantes de las tácticas de la protesta en Chile. Revista Política y Gobierno, 23(1), 163-199.

Petrone, F. (2009, noviembre). Estudios de Agenda Setting. Conceptos, metodologías y abordajes posibles. 5ta Jornada de Jóvenes Investigadores, Instituto de Investigación Gino Germani. Universidad de Buenos Aires, Argentina.
Quecedo, R. \& Castaño, C. (2002). Introducción a la metodología de investigación cualitativa. Revista Psicodidáctica, 14(1), 5-39.

Santander, P. (2011). Por qué y cómo hacer análisis de discurso. Cinta de Moebio, 41(1), 207-224. doi: 10.4067/S0717554X2011000200006

Manuscrito recibido: 05-03-2019 Manuscrito aceptado: 31-07-2019 